DOI: 10.5800/GT-2022-13-2-0582

\title{
HISTORY AND CURRENT STATE OF ANALYTICAL RESEARCH AT THE INSTITUTE OF THE EARTH'S CRUST SB RAS: CENTRE FOR GEODYNAMICS AND GEOCHRONOLOGY
}

\section{A.V. Ivanov $\oplus^{凶}$, E.I. Demonterova $\odot$, A.G. Revenko $\odot$, I.S. Sharygin $\odot$, E.A. Kozyreva $\odot$, S.V. Alexeev $\odot$}

Institute of the Earth's Crust, Siberian Branch of the Russian Academy of Sciences, 128 Lermontov St, Irkutsk 664033, Russia

ABSTRACT. The article discusses the history of the development of analytical research at the Institute of the Earth's Crust, Siberian Branch of the Russian Academy of Sciences over the past 22 years. An overview of the existing scientific equipment, current analytical techniques and some examples of their application in geological research are provided. It is shown that the availability of highly qualified personnel and modern scientific equipment at the Centre for Geodynamics and Geochronology allows, both entirely on its base and in cooperation with other Russian and foreign organizations, to conduct state of the art research with the publication of results in leading international journals.

KEYWORDS: TIMS; LA-ICPMS; XRF; XRD; AAS; Noble gas mass-spectrometry; Raman spectroscopy; cavity ring-down spectroscopy; laser diffraction analysis

FUNDING: This study was carried out as part of the grant 075-15-2021-682.

\section{REVIEW}

Received: December 10, 2021

FOR CITATION: Ivanov A.V., Demonterova E.I., Revenko A.G., Sharygin I.S., Kozyreva E.A., Alexeev S.V., 2022. History and current state of analytical research at the Institute of the Earth's Crust SB RAS: Centre for geodynamics and geochronology. Geodynamics \& Tectonophysics 13 (2), 0582. doi:10.5800/GT-2022-13-2-0582 


\title{
ИСТОРИЯ И СОВРЕМЕННОЕ СОСТОЯНИЕ АНАЛИТИЧЕСКИХ ИССЛЕДОВАНИЙ В ИНСТИТУТЕ ЗЕМНОЙ КОРЫ СО РАН: ЦЕНТР КОЛЛЕКТИВНОГО ПОЛЬЗОВАНИЯ «ГЕОДИНАМИКА И ГЕОХРОНОЛОГИЯ»
}

\author{
А.В. Иванов, Е.И. Демонтерова, А.Г. Ревенко, И.С. Шарыгин, \\ Е.А. Козырева, С.В. Алексеев
}

Институт земной коры СО РАН, 664033, Иркутск, ул. Лермонтова, 128, Россия

\begin{abstract}
АННОТАЦИЯ. В статье рассмотрена история развития аналитических исследований в ИЗК СО РАН за последние 22 года. Проведен обзор существующего научного оборудования, действующих аналитических методик, и приведены некоторые примеры их применения в геологических исследованиях. Показано, что наличие высококвалифицированных кадров и современного научного оборудования в ЦКП «Геодинамика и геохронология» позволяет как полностью на собственной базе, так и в кооперации с другими российскими и зарубежными организациями проводить исследования мирового уровня с публикацией результатов в ведущих международных изданиях.
\end{abstract}

КЛЮЧЕВЫЕ СЛОВА: МС-ТИ; МС-ИСП-ЛА; РФА; РСА; АА; масс-спектрометрия благородных газов; Рамановская спектроскопия; изотопный анализ воды; лазерная дифракция частиц

ФИНАНСИРОВАНИЕ: Работа выполнена в рамках гранта № 075-15-2021-682.

\section{1. ВВЕДЕНИЕ}

24 февраля 1949 г. в Иркутске был создан ВосточноСибирский филиал Академии наук СССР (ВСФ АН СССР), а в июле того же года - Институт геологии ВСФ АН СССР, переименованный в 1961 г. в Институт земной коры (ИЗК) СО АН СССР. Численность института в момент создания составляла всего шесть человек, а на дату переименования в структуре института действовало уже 17 самостоятельных научных подразделений. При этом три подразделения - лаборатория физических методов исследований, химико-аналитическая лаборатория и кабинет спектрального анализа - составили основу отдела аналитических лабораторий [Sklyarov, Dorofeeva, 2009; Gladkochub, Dorofeeva, 2019]. Таким образом, с самого начала деятельности института была признана необходимость подкреплять геологические исследования данными, получаемыми на собственной аналитической базе.

За годы существования института происходила неоднократная реструктуризация - объединялись и расформировывались существующие аналитические лаборатории, создавались новые. Так, в 1998 г. все они были объединены в Аналитический центр [Revenko, 2014], который в 2015 г. был реорганизован в Центр коллективного пользования (ЦКП) «Геодинамика и геохронология». Очевидно, что деятельность ЦКП «Геодинамика и геохронология» неразрывно связана с предшествующей историей развития аналитических подразделений института. В этой статье рассматривается развитие аналитики в Институте земной коры Сибирского отделения Российской академии наук (ИЗК СО РАН) за последние 22 года. Более ранняя история описана в статье [Revenko, 2014] и монографиях [Sklyarov, Dorofeeva, 2009; Gladkochub, Dorofeeva, 2019].

\section{2. МАТЕРИАЛЬНО-ТЕХНИЧЕСКАЯ БАЗА}

\section{1. Начало новой эры: 1999 г.}

По очевидным причинам во времена СССР аналитические лаборатории института преимущественно укомплектовывались научным оборудованием отечественного производства и стран социалистического лагеря. После распада СССР в связи с постоянным недофинансированием ситуация с научным оборудованием оказалась крайне сложной. Старое оборудование морально устаревало и выходило из строя по техническим причинам, а новое оборудование не закупалось. Из действующего оборудования тех времен в настоящее время остался только рентгеновский дифрактометр ДРОН-3 (рис. 1). Переломным моментом стала закупка современного (на тот момент) научного оборудования по кредиту, выданному РФ специально на эти цели правительством Германии. Так, в 1999 г. в ИЗК СО РАН появился масс-спектрометр с термической ионизацией Finnigan MAT262 (рис. 2), а спустя десять лет за счет программы поддержки материально-технической базы Российского фонда фундаментальных исследований (РФФИ) сотрудниками института был спроектирован и создан блок чистых комнат класса 1000 (рис. 3), в которых осуществляется пробоподготовка для высокоточных изотопных анализов.

\section{2. Устойчивое развитие: середина 2000-x - 2018 г.}

С середины 2000-х и до реформы Российской академии наук в 2013 г. основное обновление научного оборудования в институте осуществлялось по линии Приборной комиссии СО РАН. После реформы РАН Министерство науки и образования (МOH) в течение двух лет завершило выполнение ранее заключенных соглашений этой комиссии. Из наиболее дорогостоящего 


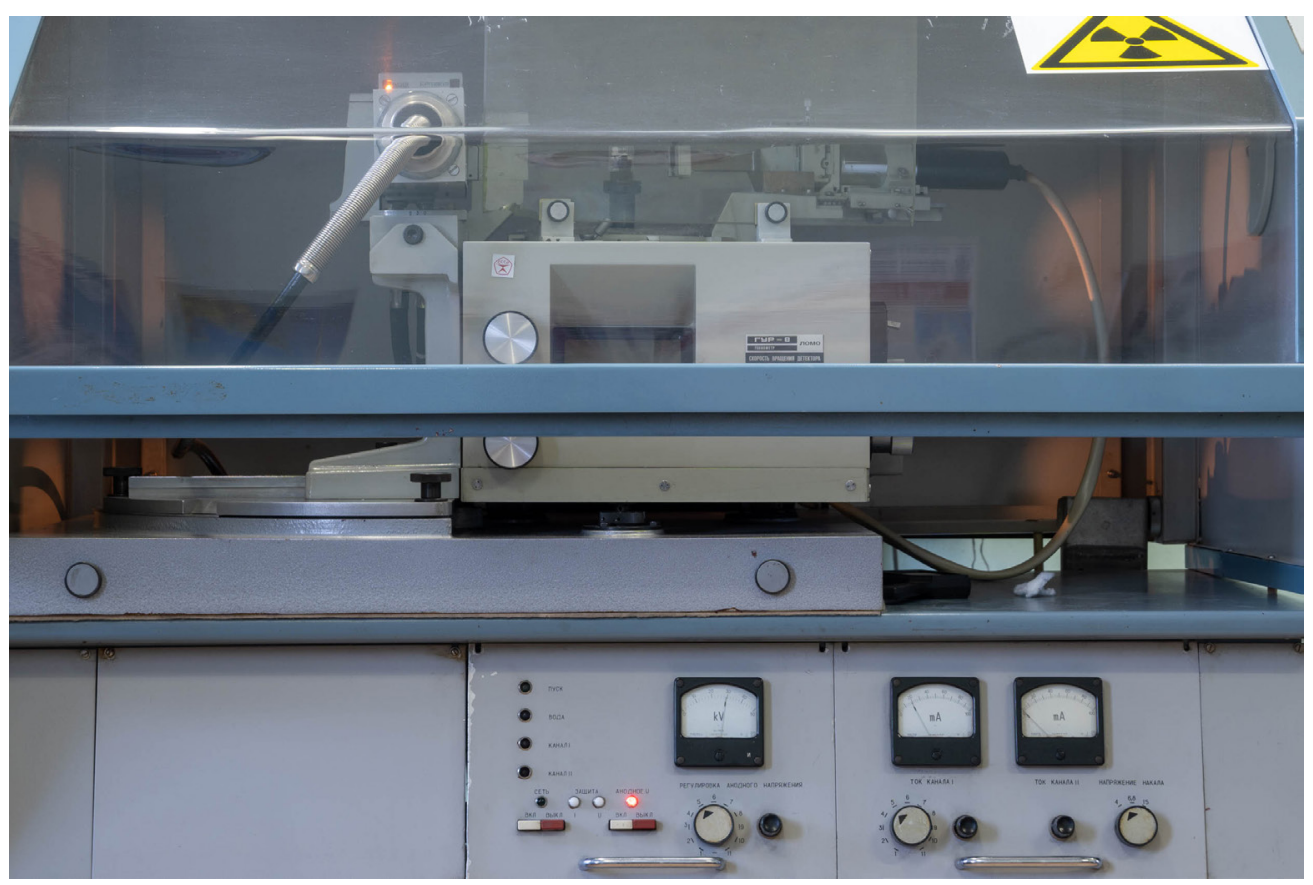

Рис. 1. Рентгеновский дифрактометр ДРОН-3 (Буревестник, Россия). Предназначен для определения кристаллических структур, установления фазового состава полиминеральных смесей, в частности глин.

Fig. 1. X-ray diffractometer DRON-3 (Burevestnik, Russia). Designed to determining the crystalline structures, to analyze the phase composition of polymineral mixtures, in particular clays.

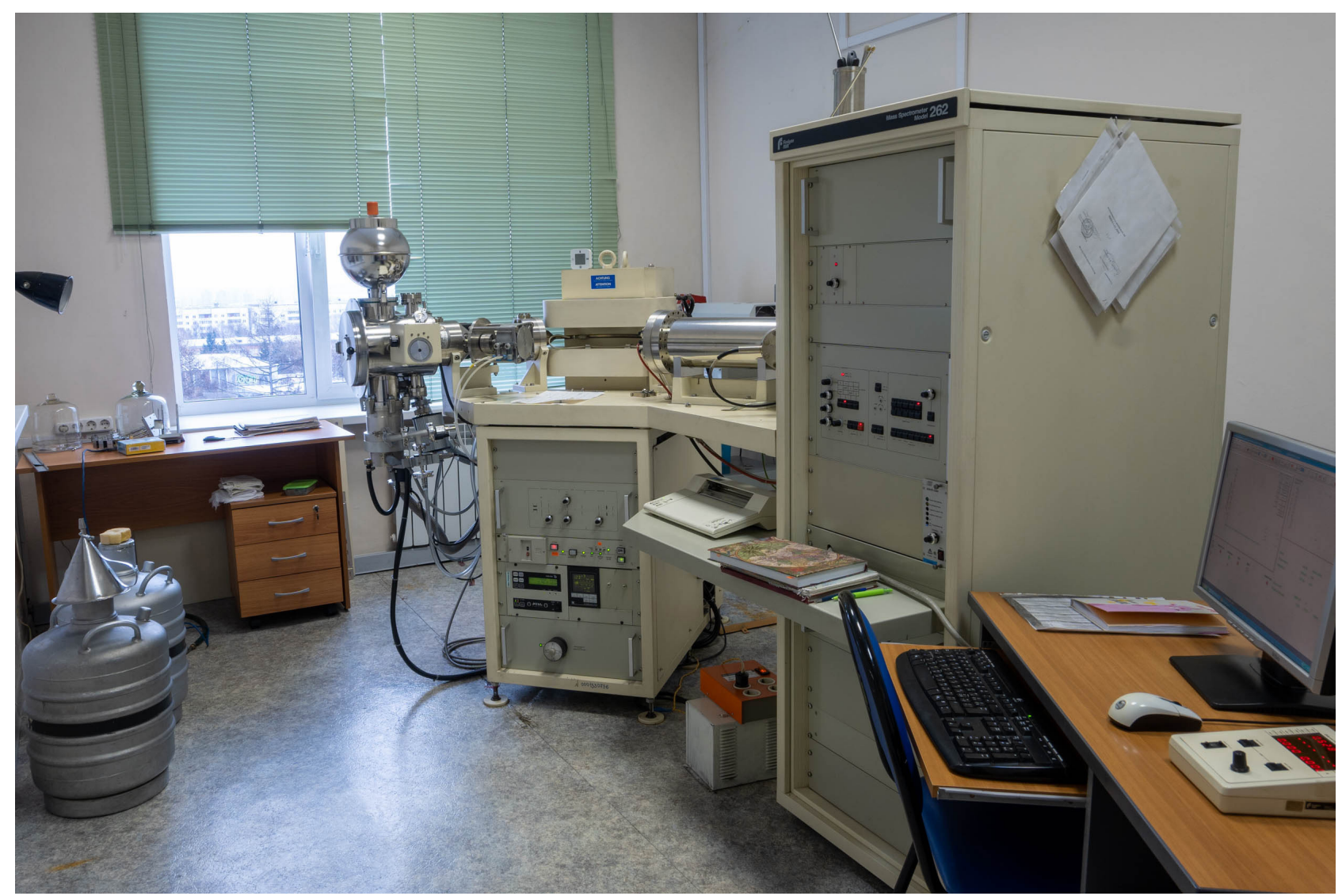

Рис. 2. Масс-спектрометр с термической ионизацией Finnigan MAT262 (Finnigan, Германия). Предназначен для прецизионных изотопных измерений элементов, в частности $\mathrm{Rb}, \mathrm{Sr}, \mathrm{Sm}, \mathrm{Nd}, \mathrm{Pb}$ и $\mathrm{U}$.

Fig. 2. Thermal ionization mass-spectrometer Finnigan MAT262 (Finnigan, Germany). Designed to precision isotopic measurements of elements, in particular $\mathrm{Rb}, \mathrm{Sr}, \mathrm{Sm}, \mathrm{Nd}, \mathrm{Pb}$ and $\mathrm{U}$. 


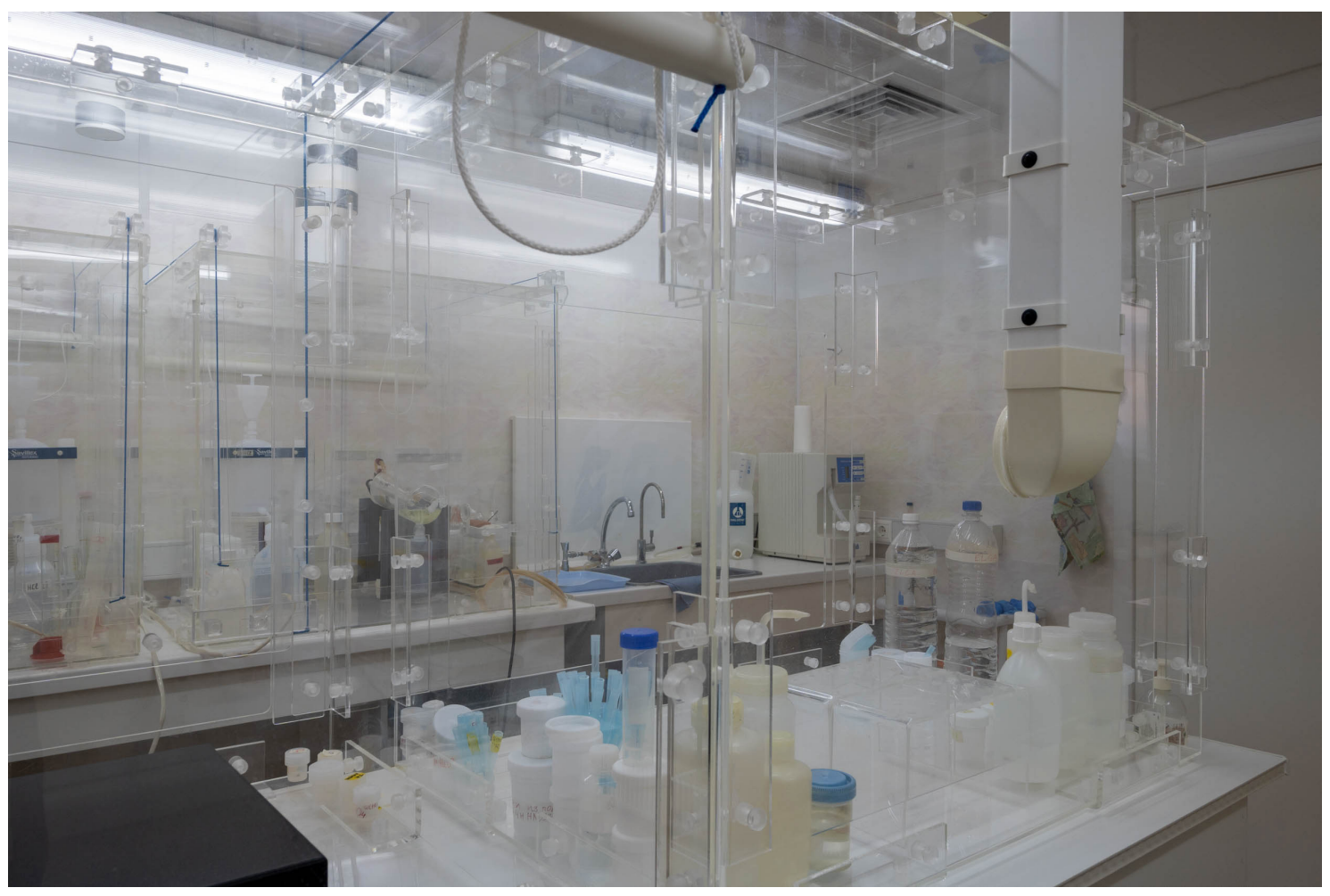

Рис. 3. Блок чистых комнат класса 1000 оригинальной конструкции. Предназначен для химпробоподготовки для изотопных исследований.

Fig. 3. Class 1000 clean room with an original design. Designed for chemical sample preparation for isotope studies.

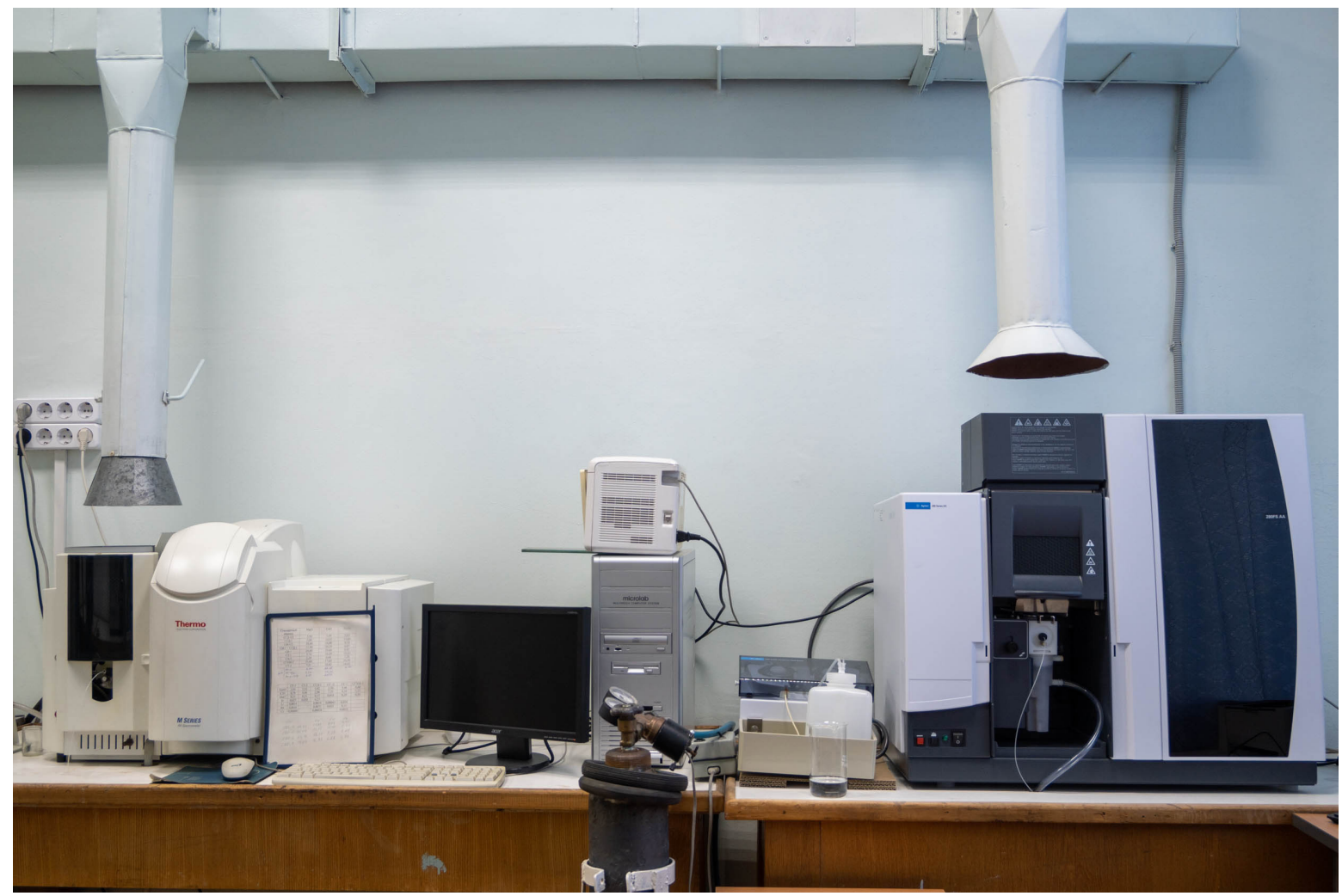

Рис. 4. Атомно-абсорбционные спектрометры: слева - Solaar M6 (Thermo Fisher Scientific, США), cправа - 280FS (Agilent, CША). Предназначены для силикатного анализа горных пород и для анализа природных вод.

Fig. 4. Atomic absorption spectrometers: on the left - Solaar M6 (Thermo Fisher Scientific, USA), on the right - 280FS (Agilent, USA). Designed for determination of major element composition of rocks and the analysis of natural waters. 


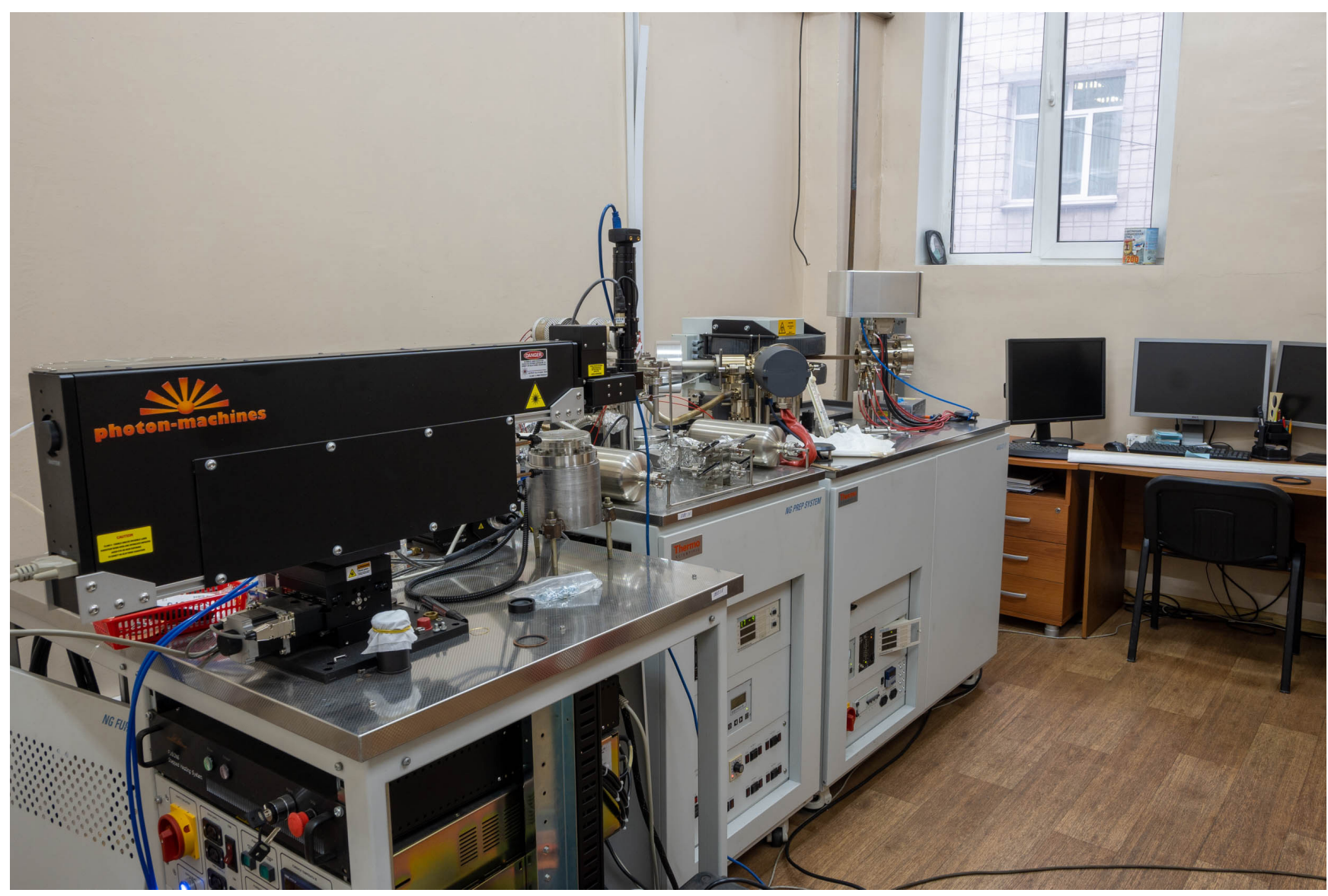

Рис. 5. Масс-спектрометрический комплекс Argus VI (Thermo Fisher Scientific, США) и углекислотный лазер с длиной волны 10.6 мкм (Teledyne Photon Machines, США). Предназначен для K-Ar и ${ }^{40} \mathrm{Ar} /{ }^{39} \mathrm{Ar}$ датирования.

Fig. 5. Mass spectrometric complex Argus VI (Thermo Fisher Scientific, USA) and a $\mathrm{CO}_{2}$ laser with a wavelength of $10.6 \mu \mathrm{m}$ (Teledyne Photon Machines, USA). Designed for K-Ar and ${ }^{40} \mathrm{Ar} /{ }^{39} \mathrm{Ar}$ dating.

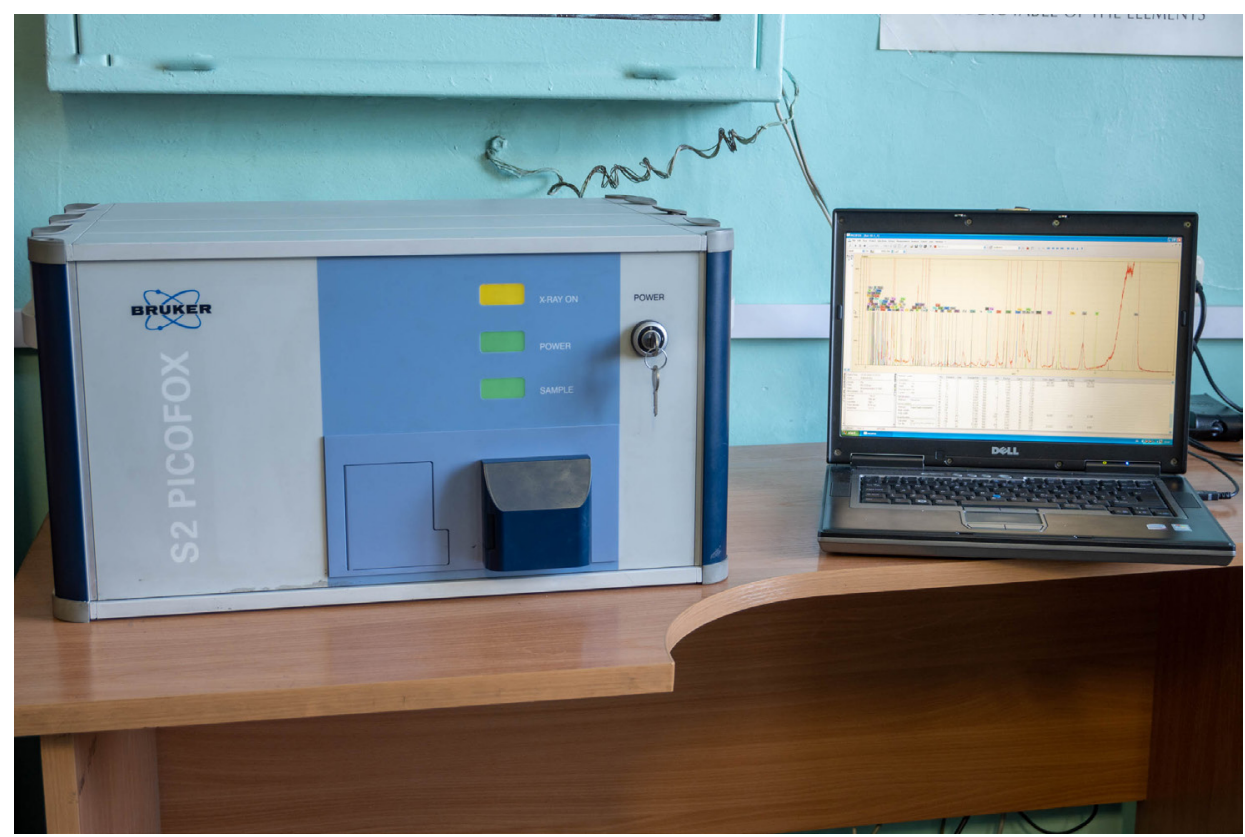

Рис. 6. Рентгенофлуоресцентный спектрометр с полным внешним отражением S2 PICOFOX (Bruker, Германия). Предназначен для определения содержаний основных и примесных элементов в малых количествах жидких и твердых образцов.

Fig. 6. Total reflection X-ray fluorescence spectrometer S2 PICOFOX (Bruker, Germany). Designed to determine major and trace element concentrations in small amounts of liquid and solid samples. 


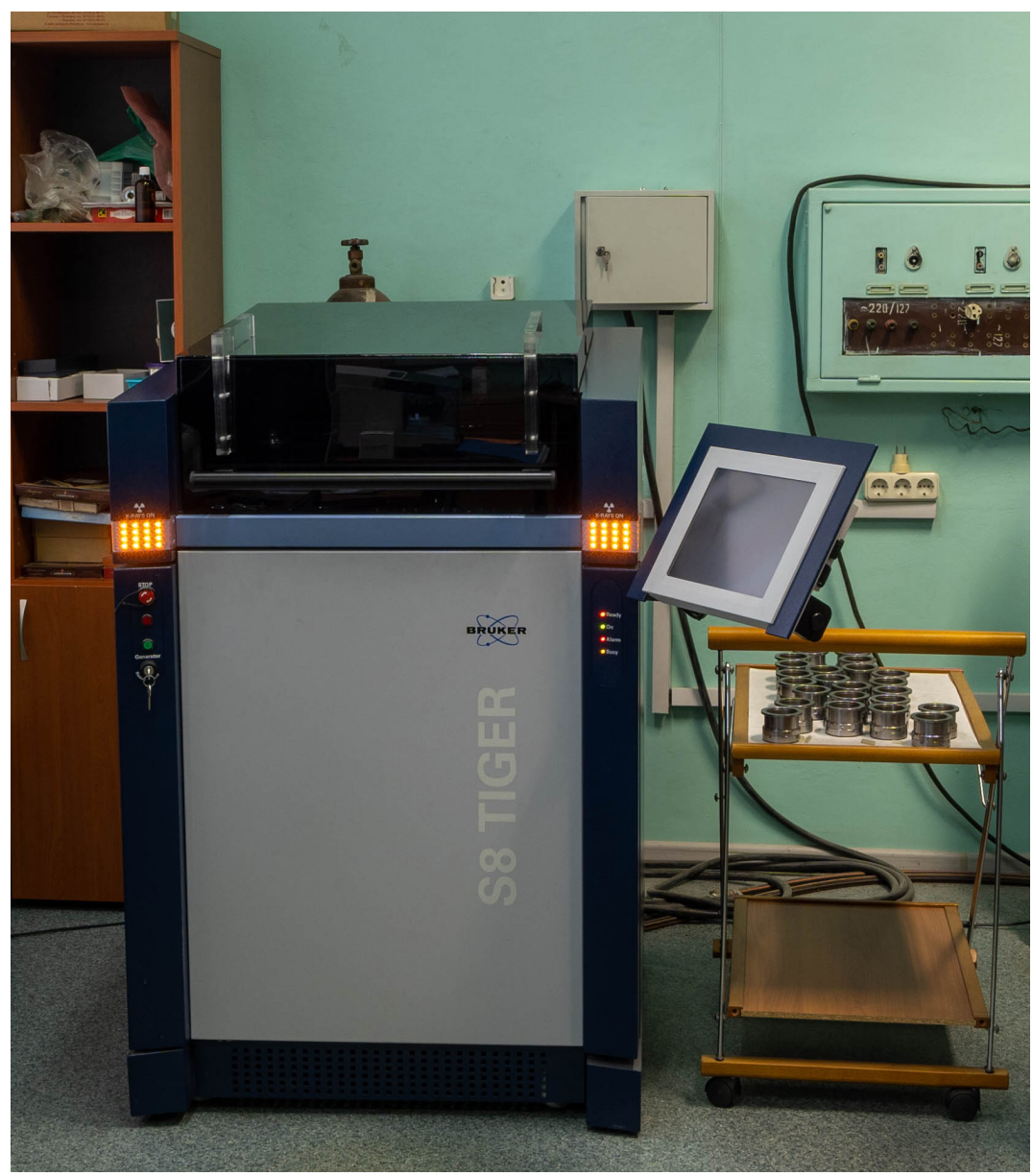

Рис. 7. Волнодисперсионный рентгенофлуоресцентный спектрометр S8 TIGER (Bruker, Германия). Предназначен для определения содержаний основных и примесных элементов в горных породах, почвах и других природных и искусственных средах.

Fig. 7. Wavelength dispersive X-ray fluorescence spectrometer S8 TIGER (Bruker, Germany). Designed to determine major and trace element concentrations in rocks, soils and other natural and artificial samples.

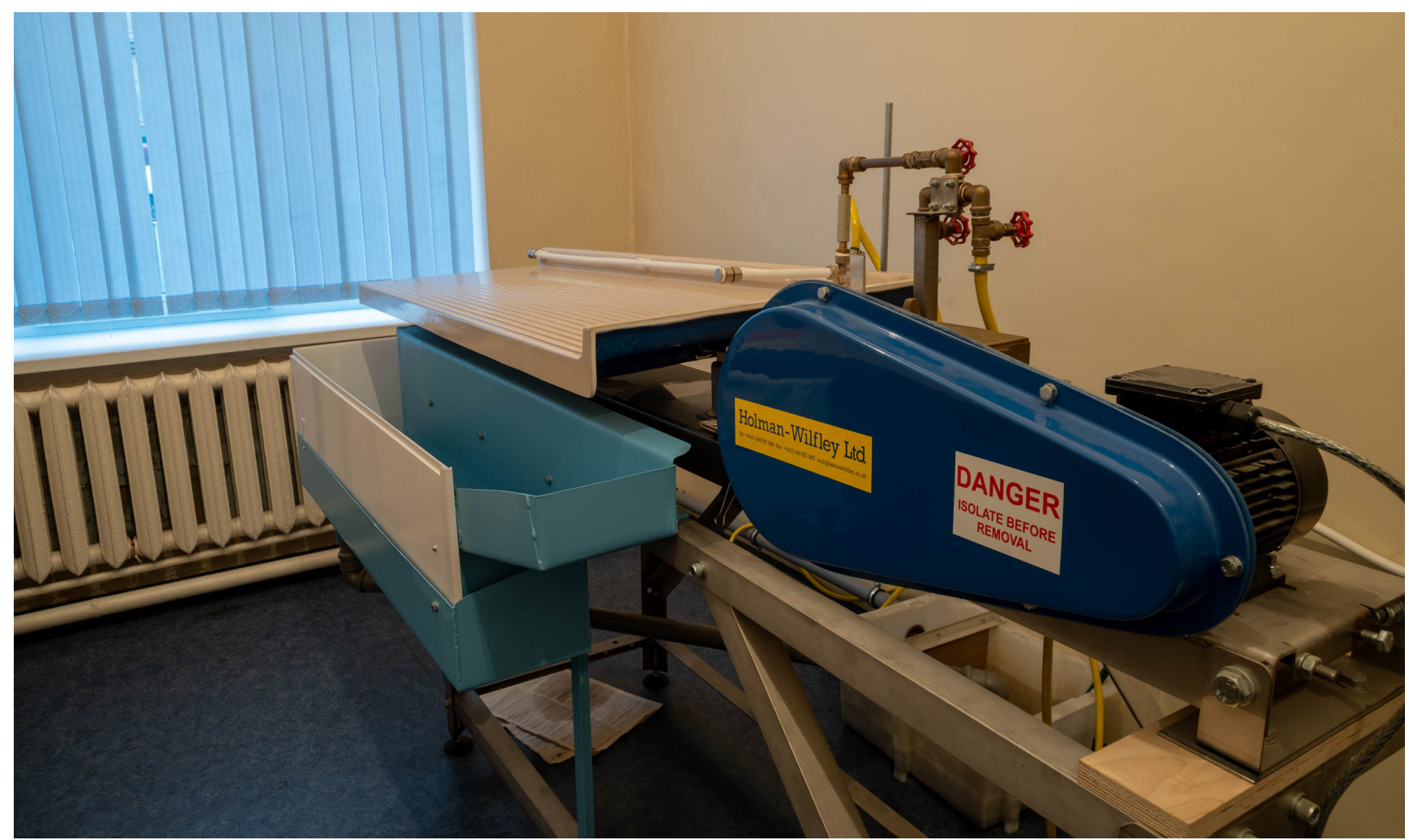

Рис. 8. Концентрационный стол Holman 8000 (Holman-Wilfley, Великобритания). Специализирован для выделения бадделеита. Fig. 8. Water-flow table Holman 8000 (Holman-Wilfley, Great Britain). Specialized for the isolation of baddeleyite grains. 
оборудования в эти годы были приобретены атомноабсорбционный спектрометр Solar M6 (рис. 4), массспектрометрический комплекс Argus VI и углекислотный лазер с длиной волны 10.6 мкм (рис. 5), рентгенофлуоресцентные спектрометры S2 PICOFOX (рис. 6) и S8 TIGER (рис. 7). В эти же годы осуществлялась закупка относительно недорогого (до 1.5 млн руб.) оборудования за счет средств грантов РФФИ, РНФ и хоздоговоров. Например, таким образом был приобретен концентрационный стол Holman 8000 (рис. 8), ряд оптических поляризационных и бинокулярных микроскопов, оборудование для пробоподготовки (рис. 9), полуавтоматический гидравлический пресс HERZOG HTP-40, усовершенствована система регистрации спектрографа ДФС-13 и т.П..

\section{3. Ускоренное развитие: 2018-2021 гг.}

В 2018 г. в Российской Федерации была запущена программа развития передовой инфраструктуры для проведения исследований и разработок в рамках национального проекта «Наука». Эта программа ориентирована на обновление научного оборудования в институтах первой категории, к которой относится и ИЗК СО РАН. За счет средств этой программы были приобретены лазерный анализатор частиц Analysette 22 Nanotec (рис. 10) и изотопный анализатор воды Picarro L2140-і (рис. 11), в первую очередь для нужд лаборатории инженерной геологии и геоэкологии и лаборатории гидрогеологии. ЦКП «Геодинамика и геохронология» является объединяющей структурой для всего института. Он включает в себя также уникальную научную установку (УНУ) «Южно-Байкальский инструментальный комплекс для мониторинга опасных геодинамических процессов (ЮБИК)».

Важным этапом развития института стала победа в 2019 г. в седьмом конкурсе мегагрантов (по Постановлению Правительства РФ р 220), в рамках мегагранта создана лаборатория орогенеза под руководством известного ученого С.А. Писаревского. По этому проекту было закуплено и установлено следующее оборудование: конфокальный Рамановский спектрометр WITec Alpha300 R (рис. 12) и масс-спектрометр с индуктивно связанной плазмой Agilent 7900, соединенный с системой лазерной абляции Analyte Excite (рис. 13). Организована комната оптической микроскопии и подготовки образцов для локальных методов исследования (рис. 14).

В 2021 г. институт оказался одним из победителей в конкурсе развития инфраструктуры научной, научнотехнической деятельности (ЦКП, УНУ) государственной программы «Научно-технологическое развитие Российской Федерации». За счет этих средств приобретены рентгенофлуоресцентный спектрометр T-Star и автоматизированный испытательный комплекс ACИC.

\section{3. МЕТОДЫ}

В ЦКП «Геодинамика и геохронология» используются следующие основные аналитические методы:
1. Масс-спектрометрический с термической ионизацией (МС-ТИ) - масс-спектрометр Finnigan MAT262 (см. рис. 2), блок чистых комнат класса 1000 (ISO6) (см. рис. 3). Определение изотопного состава $\mathrm{Sr}, \mathrm{Nd}, \mathrm{Pb}$, определение концентраций $\mathrm{Sm}, \mathrm{Nd}, \mathrm{Rb}, \mathrm{Sr}$ методом изотопного разбавления в горных породах, минералах, природных водах и артефактах.

2. Масс-спектрометрический с электронной ионизацией (МС-ЭИ) - масс-спектрометрический комплекс ARGUS VI, инфракрасный $\mathrm{CO}_{2}$ лазер с длиной волны 10.6 мкм (см. рис. 5). K-Ar и ${ }^{40} \mathrm{Ar} /{ }^{39} \mathrm{Ar}$ датирование.

3. Масс-спектрометрический с индуктивно связанной плазмой (МС-ИСП) с использованием растворов и лазерной абляции - масс-спектрометр Agilent 7900, эксимерный лазер Analyte Excite (см. рис. 13). Определение широкого спектра редких элементов в горных породах и минералах, $\mathrm{U}-\mathrm{Pb}$ датирование минералов.

4. Рентгенофлуоресцентный анализ (РФА) - спектрометры S2 PICOFOX (см. рис. 6), S8 TIGER (см. рис. 7) и T-STAR. Определение породообразующих и редких элементов в горных породах, почвах, озерных отложениях, других природных и искусственных объектах.

5. Рентгеноструктурный анализ (РСА) - дифрактометр ДРОН-3 (см. рис. 1). Установление структуры минералов, определение фазового состава полиминеральных смесей, в частности глин.

6. Силикатный анализ, использующий комплекс методов: атомно-абсорбционный, спектрофотометрический, гравиметрический, титриметрический и потенциометрический - спектрофотометры Genesys, Solaar M6 и 280FS (см. рис. 4). Определение породообразующих элементов в горных породах.

7. Конфокальная Рамановская спектроскопия - система WITec Alpha300 R (см. рис. 12). Изучение вещества локальным недеструктивным методом.

8. Гранулометрия - лазерный анализатор частиц Analysette 22 Nanotec (см. рис. 10). Определение размеров частиц в рыхлых отложениях и техногенных продуктах.

9. Общий и специальный анализ химического состава подземных вод, включающий титриметрический, весовой, колориметрический, атомно-абсорбционный и спектрофотометрический методы - спектрофотометры Genesys и Solaar M6 (см. рис. 4). Определение содержания макро- и микрокомпонентов в подземных водах.

10. Изотопный анализ воды - анализатор Picarro L2140-i (см. рис. 11). Определение изотопного состава кислорода $\left(\delta^{17} \mathrm{O}\right.$ и $\left.\delta^{18} \mathrm{O}\right)$ и водорода $(\delta \mathrm{D})$ в воде.

11. Определение механических свойств грунтов и твердых пород - автоматизированный испытательный комплекс АСИС, позволяющий анализировать механические свойства дисперсных, крупнообломочных, мерзлых грунтов и скальных пород.

\section{4. НЕКОТОРЫЕ НАУЧНЫЕ РЕЗУЛЬТАТЫ}

Учитывая большой объем научных результатов, полученный с момента создания ЦКП «Геодинамика и геохронология» в 2015 г., не говоря уже о результатах, 


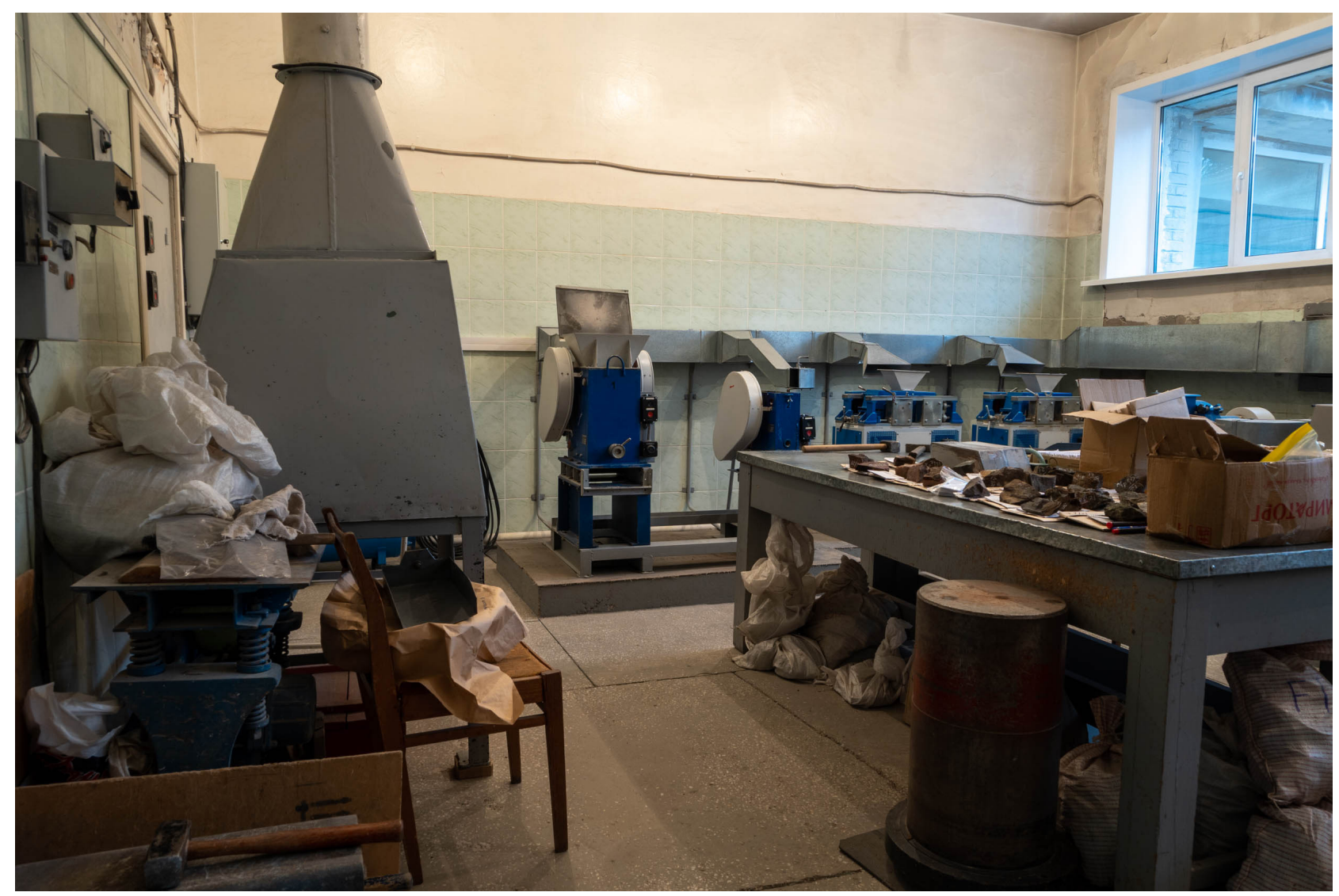

Рис. 9. Кабинет пробоподготовки, оборудованный дробилками и истирателями. Предназначен для первичной пробоподготовки горных пород.

Fig. 9. Sample preparation room equipped with crushers and grinders. Designed for initial sample preparation of rocks.

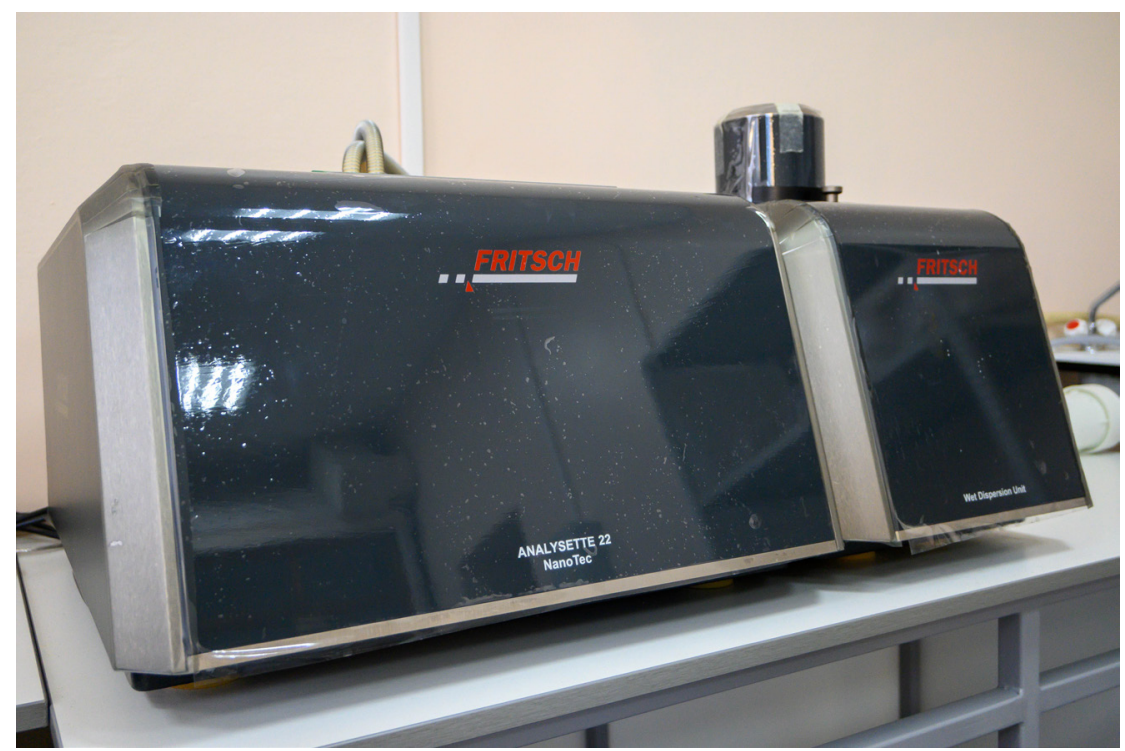

Рис. 10. Лазерный анализатор частиц Analysette 22 Nanotec (Fritsch, Германия). Предназначен для определения размеров частиц в рыхлых отложениях и техногенных продуктах.

Fig. 10. Laser diffraction particle analyzer Analysette 22 Nanotec (Fritsch, Germany). Designed to determine the size of particles in loose sediments and artificial products. 


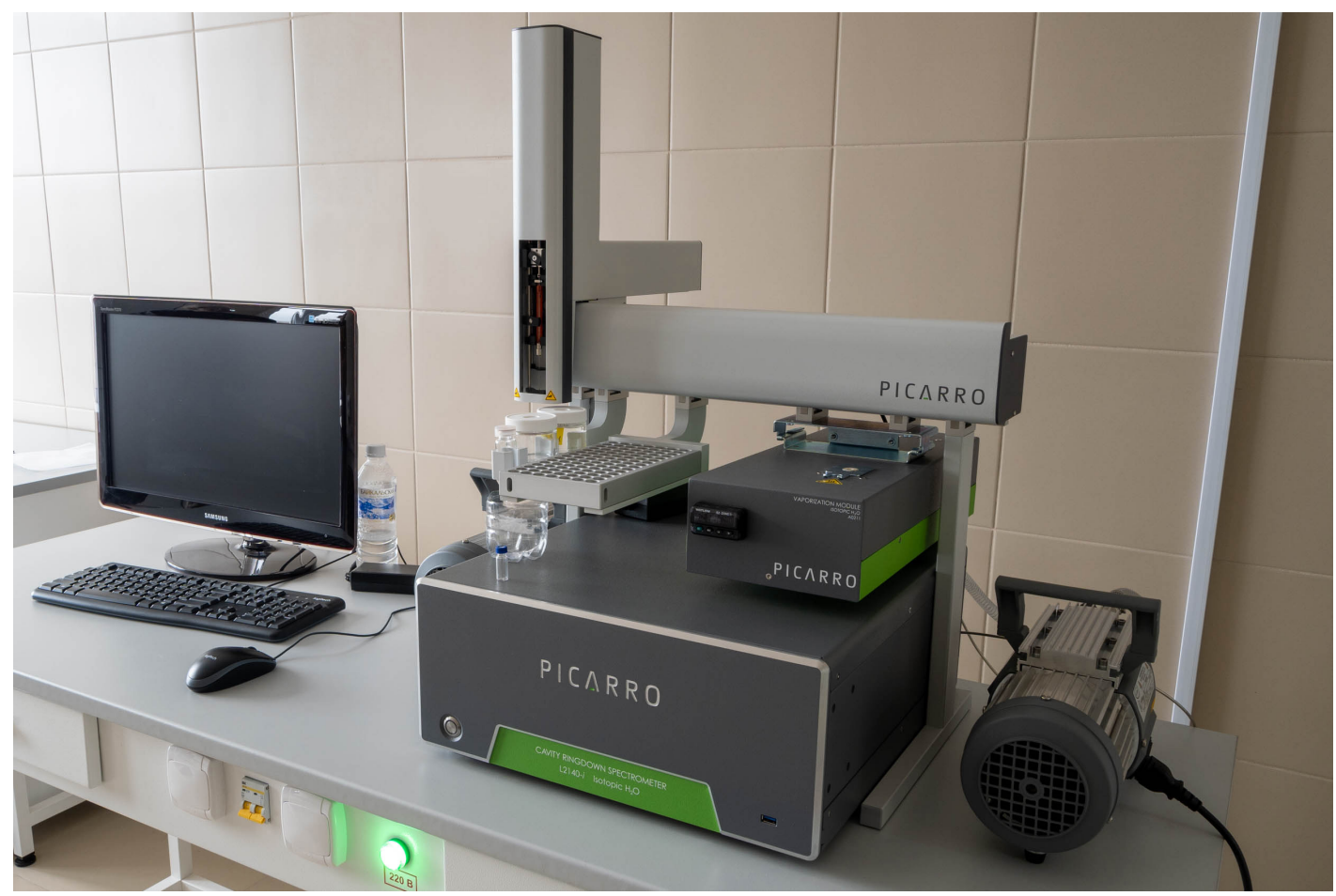

Рис. 11. Изотопный анализатор воды Picarro L2140-i (Picarro, CША). Предназначен для определения $\delta \mathrm{D}, \delta^{17} \mathrm{O}$ и $\delta^{18} \mathrm{O}$ в воде. Fig. 11. Cavity ring-down isotope analyzer Picarro L2140-i (Picarro, USA). Designed to determine $\delta \mathrm{D}, \delta^{17} \mathrm{O}$ and $\delta^{18} \mathrm{O}$ in water.

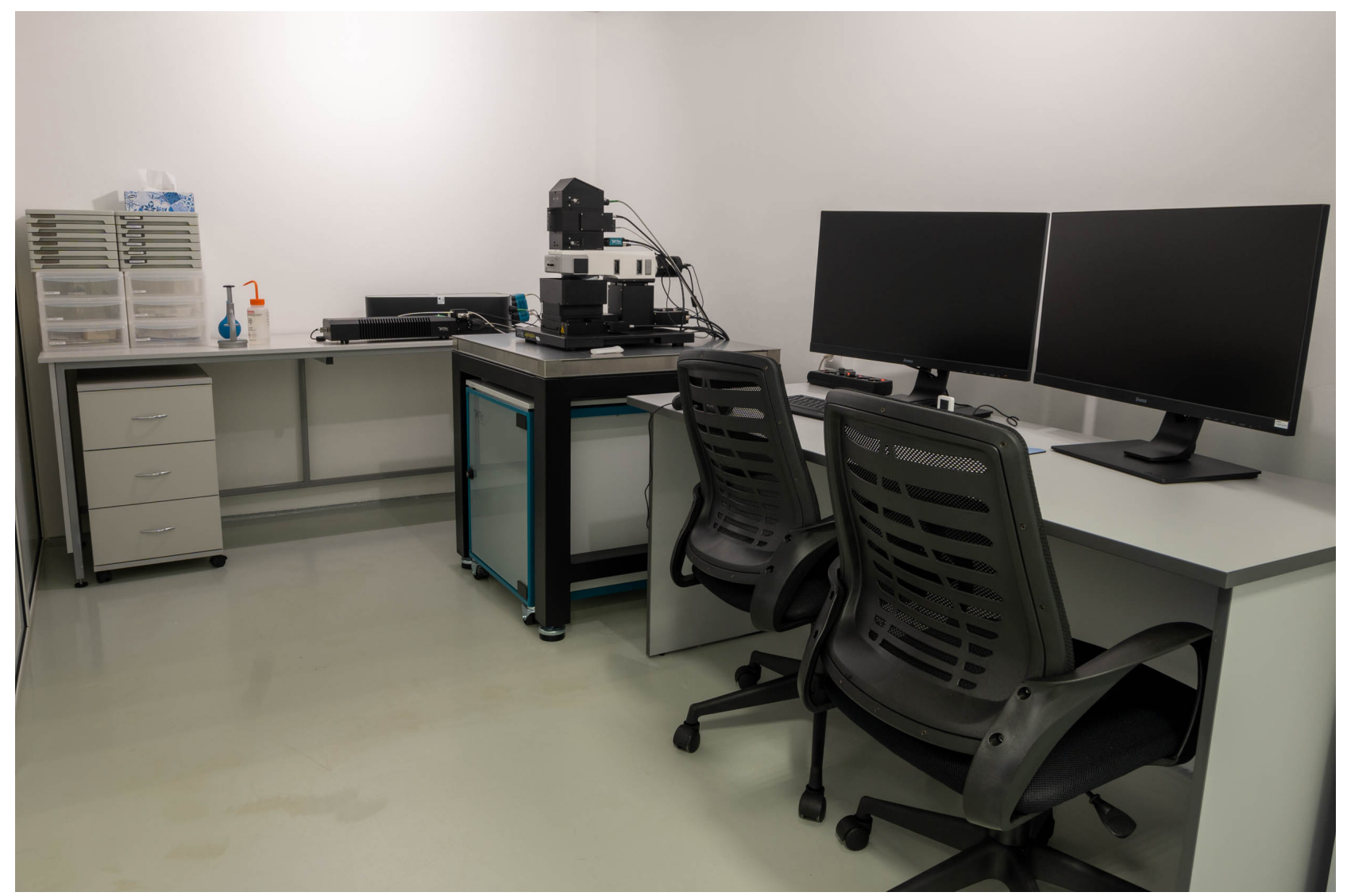

Рис. 12. Рамановский спектрометр WITec Alpha300 R (Witec, Германия). Предназначен для изучения вещества методом конфокальной Рамановской спектроскопии.

Fig. 12. Raman spectrometer WITec Alpha300 R (Witec, Germany). Designed for the study of matter by the method of confocal Raman spectroscopy. 


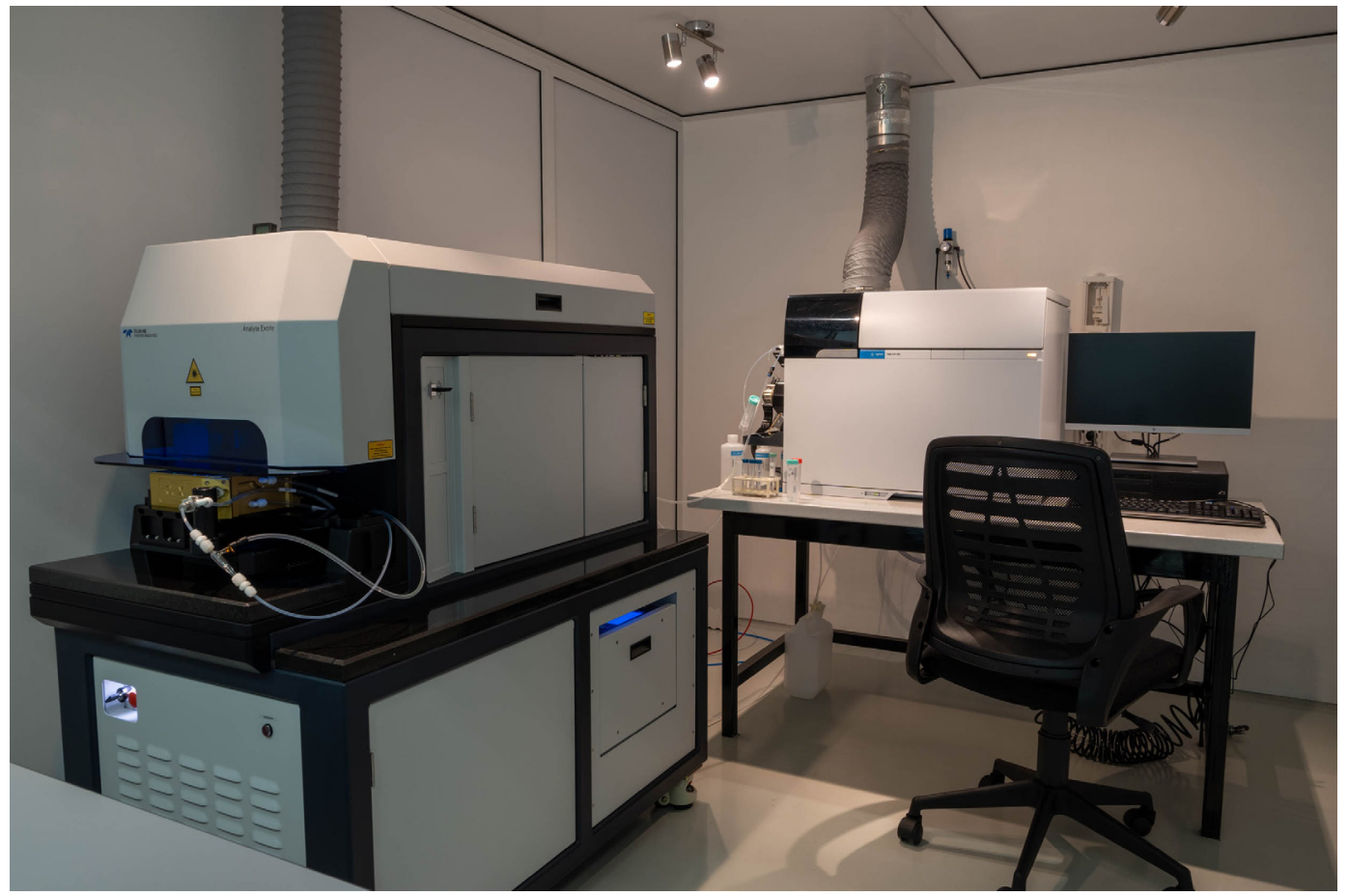

Рис. 13. Масс-спектрометр с индуктивно связанной плазмой Agilent 7900 (Agilent, США) (на дальнем плане) и система лазерной абляции Analyte Excite (Cetac Teledyne, США) (на переднем плане). Предназначены для определения концентраций широкого спектра элементов в растворах и твердых образцах, а также U-Pb датирования минералов методом лазерной абляции.

Fig. 13. Inductively coupled plasma mass spectrometer Agilent 7900 (Agilent, USA) (background) and Analyte Excite laser ablation system (Cetac Teledyne, USA) (in front). Designed to determine the concentrations of a wide range of elements in solutions and solid samples, as well as for U-Pb dating of minerals by laser ablation.

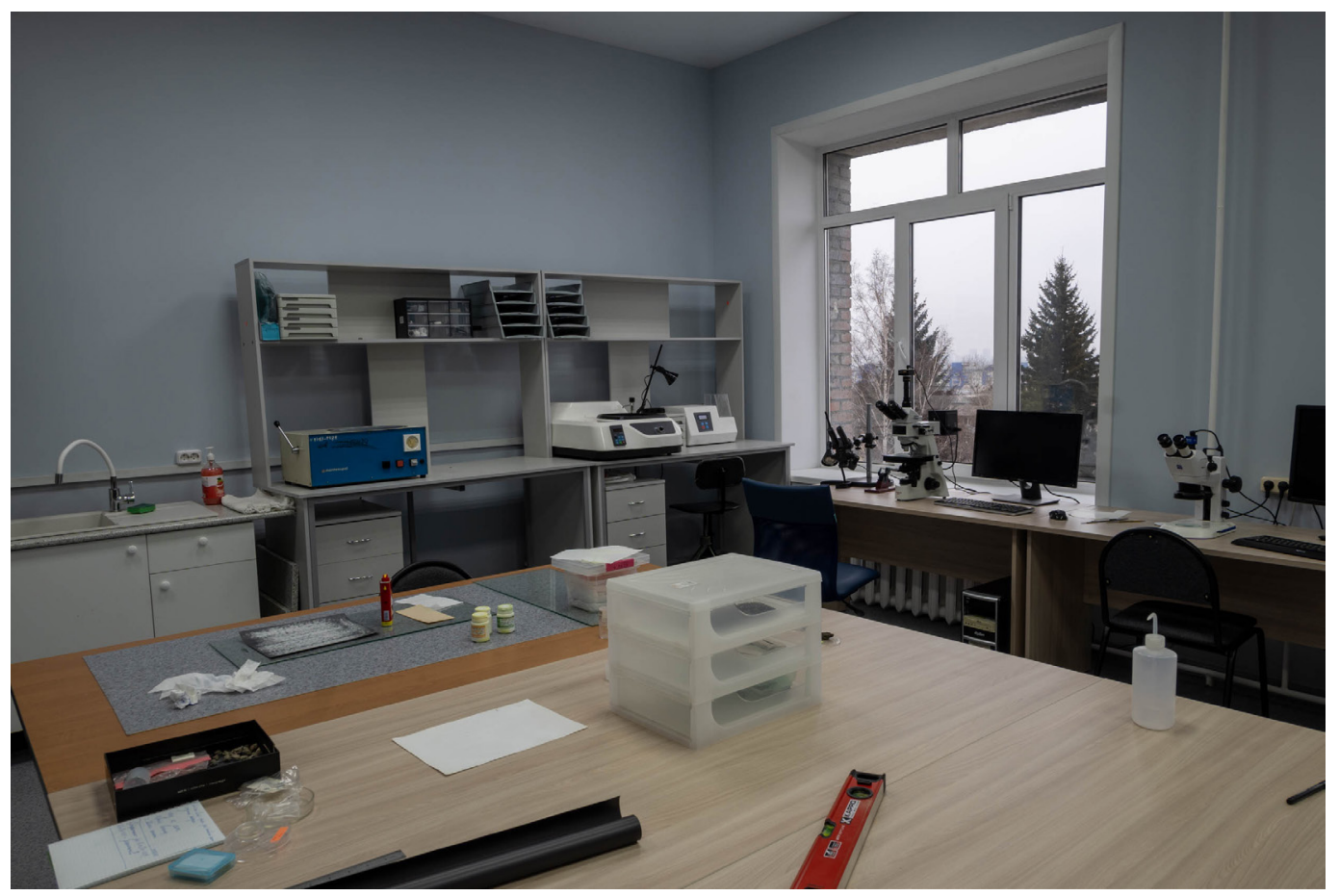

Рис. 14. Комната оптической микроскопии и пробоподготовки.

Предназначена для петрографического описания шлифов, отбора мономинеральных фракций под бинокулярным микроскопом, изготовления шашек из эпоксидной смолы с вмонтированными пробами и т.д.

Fig. 14. Optical microscopy and sample preparation room.

Designed for petrographic description of thin sections, selection of mineral fractions under a binocular microscope, making epoxy resin mounts with embedded samples, etc. 
аккумулированных за все время существования аналитических лабораторий в институте, остановимся кратко только на некоторых примерах.

Метод масс-спектрометрии с термической ионизацией в институте является востребованным для изотопно-геохимических исследований магматических [Donskaya et al., 2018; Ivanov et al., 2018, 2019; Kutyrev et al., 2021; Sheth et al., 2019], метаморфических [Donskaya et al., 2017; Vanin et al., 2018] и осадочных [Demonterova et al., 2017, 2018] пород, а также для Sm-Nd датирования [Savelyeva et al., 2016]. На рис. 15 приведен пример изучения юрских отложений Иркутского бассейна, расположенного на юге Сибирской платформы [Demonterova et al., 2017]. Так, песчаники более древней присаянской свиты характеризуются широким разбросом повышенных значений $\mathrm{Ni} / \mathrm{Zr}$ (0.28-1.33) при низких значениях $\varepsilon \mathrm{Nd}_{(\text {т) }}$ (ниже -15) и соответствующих значениях Sm-Nd модельного возраста (древнее 2.2 млрд лет). Из этих данных можно сделать заключение, что в источнике сноса осадочного материала присаянской свиты преобладали породы древнего фундамента Сибирской платформы, причем среди них были породы как кислого, так и основного состава, что отражается, соответственно, в низких и высоких значениях $\mathrm{Ni} / \mathrm{Zr}$. Песчаники более молодых свит - кудинской и котовской - показывают тренд снижения $\mathrm{Ni} / \mathrm{Zr}$ от 0.24 до 0.07 при росте значений $\varepsilon \mathrm{Nd}_{(\mathrm{T})}$ от -14 до +0.4 , что соответствует снижению Sm-Nd модельного возраста до 875 млн лет. Этот тренд проинтерпретирован как изменение древнего источника сноса смешанного состава на молодой источник сноса с кислой ювенильной корой. Такая молодая ювенильная кора начала выводиться на поверхность в Забайкалье (к югу от Сибирской платформы в современных координатах) в результате роста гор, связанного с закрытием МонголоОхотского океана [Demonterova et al., 2017].

K-Ar и ${ }^{40} \mathrm{Ar} /{ }^{39} \mathrm{Ar}$ методы в институте используются для датирования преимущественно магматических пород [Ivanov et al., 2018, 2019; Li et al., 2018; Savelyeva et al., 2016; Sheth et al., 2019] и, реже, метаморфических [Reznitsky et al., 2015] процессов. В качестве показательного примера можно привести датирование траппов Эмейшань (Китай) [Li et al., 2018; Jicha et al., 2019]. Предшествующее ${ }^{40} \mathrm{Ar} /{ }^{39} \mathrm{Ar}$ датирование траппов Эмейшань показывало существенный разброс датировок в сторону омоложения от истинного возраста изза интенсивных вторичных изменений. Подавляющее большинство U-Pb датировок по циркону было получено по интрузивам, не имеющим однозначной корреляции с лавовыми толщами. Во время полевых работ сотрудникам ИЗК СО РАН совместно с китайскими коллегами удалось найти неизмененный лавовый поток плагиофировых базальтов, который был датирован ${ }^{40} \mathrm{Ar} /{ }^{39} \mathrm{Ar}$ методом по плагиоклазу в трех лабораториях - Института геологии и геофизики Китайской академии наук (Китай), Университета штата Висконсин в Мэдисоне (США) и ЦКП «Геодинамика и геохронология» ИЗК СО РАН (Россия). Все три лаборатории показали идентичные значения возраста - соответственно 259.9 \pm 1.2 млн лет, $259.8 \pm 1.2$ млн лет и $261.7 \pm$ \pm 3.4 млн лет (рис. 16). В пределах погрешности эти датировки совпадают с датировками Гваделупского массового вымирания и подтверждают гипотезу, что объемные вулканические извержения могли приводить к глобальным биосферным катастрофам.

РФА в институте реализуется при помощи классического волнового спектрометра S8 TIGER (cм. pис. 7) и спектрометра с полным внешним отражением S2 PICOFOX (см. рис. 6). Для каждого из них разработан ряд оригинальных методик анализа, а также постоянно совершенствуются ранее разработанные методики, расширяется круг анализируемых объектов и определяемых элементов. В качестве примера методических исследований с применением классического РФА можно привести определение содержаний $\mathrm{Ba}$, La и Ce, которое выполняется в ИЗК СО РАН с 1990 г. В недавних работах [Suvorova et al., 2014, 2017; Khudonogova et al., 2015] подробно рассмотрены особенности выбора оптимальных условий анализа для Cs и обсуждены изменения, внесенные в ранее разработанную для спектрометра S4 PIONEER методику РФА для $\mathrm{Ba}, \mathrm{La}, \mathrm{Ce}, \mathrm{Nd}$ и Ta. Пределы обнаружения Cs, Ba, La, Ce и Nd (мкг/г) coставили соответственно 3.4, 4.3, 2.7, 5.8 и 4.7. Исследования, посвященные РФА редкоземельных руд, описаны в работах [Suvorova et al., 2016; Akhmetzhanov et al., 2021]. В частности, разработана методика определения содержаний Ga, Hf и Та применительно к образцам редкоземельных руд Катугинского месторождения (Забайкалье) с использованием спектрометра S8 TIGER [Suvorova et al., 2016]. Рассчитанные пределы обнаружения для $\mathrm{Ga}$, Hf и Та оказались равными соответственно (мкг/г) 1.6, 4.3 и 2.6. Диапазоны определяемых содержаний составили для $\mathrm{Ga}$, Hf и Та соответственно (мкг/г): 1.6-212.0, 4.3-960.0 и 2.6-5200.0. Исследования этого месторождения осуществляются геологами ИЗК СО РАН для понимания генезиса месторождения и его промышленного освоения [Gladkochub et al., 2017]. В работе [Akhmetzhanov et al., 2021] показано, что использование многомерных калибровок PLS/PCR в РФА позволяет снизить значение относительной среднеквадратичной ошибки определения редкоземельных элементов (Ce, La, Nd, Pr и Sm) в сульфидных рудах и железомарганцевых конкрециях.

В последние годы закуплено новое оборудование лазерный анализатор частиц Analysette 22 Nanotec (см. рис. 10), изотопный анализатор воды Picarro L2140-i (см. рис. 11), конфокальный Рамановский спектрометр WITec alpha300 R (см. рис. 12), масс-спектрометр Agilent 7900 и эксимерный лазер Analyte Excite (см. рис. 13). Это оборудование установлено и запущено в работу. Некоторые результаты, полученные на этом оборудовании, уже вошли в ряд публикаций: Рамановский спектрометр WITec alpha300 R [Ivanov et al., 2021; Maltsev et al., 2021; Marfin et al., 2021; Shendrik et al., 2021] и лазерный анализатор частиц Analysette 22 Nanotec [Pashkova et al., 2021; Pellinen et al., 2021a, 2021b]. 


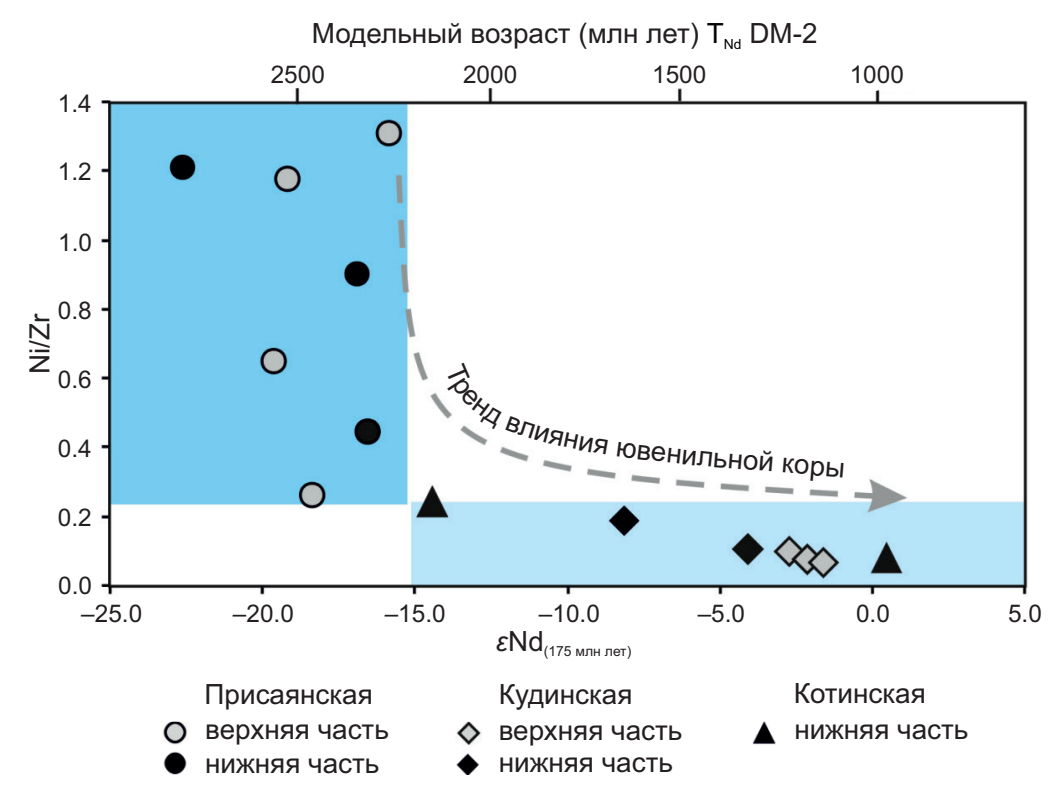

Рис. 15. Вариации $\mathrm{Ni} / \mathrm{Zr}$ и $\varepsilon \mathrm{Nd}_{(\mathrm{T})}$ в песчаниках юрских свит Иркутского бассейна [Demonterova et al., 2017].

Диаграмма демонстрирует возможность использования геохимических критериев для выявления смены источников сноса в связи с меняющимися геодинамическими процессами. Элементные отношения определены на рентгенофлуоресцентном спектрометре S8 TIGER, а изотопные отношения неодима - на масс-спектрометре Finnigan MAT262.

Fig. 15. Variations of $\mathrm{Ni} / \mathrm{Zr}$ and $\varepsilon \mathrm{Nd}_{(\mathrm{T})}$ in sandstones of the Jurassic formations of the Irkutsk basin [Demonterova et al., 2017]. The diagram demonstrates the possibility of using geochemical criteria to identify the provenance in connection with changing geodynamic processes. Elemental ratios were determined on an S8 TIGER X-ray fluorescence spectrometer, and neodymium isotopic ratios on a Finnigan MAT262 mass spectrometer.

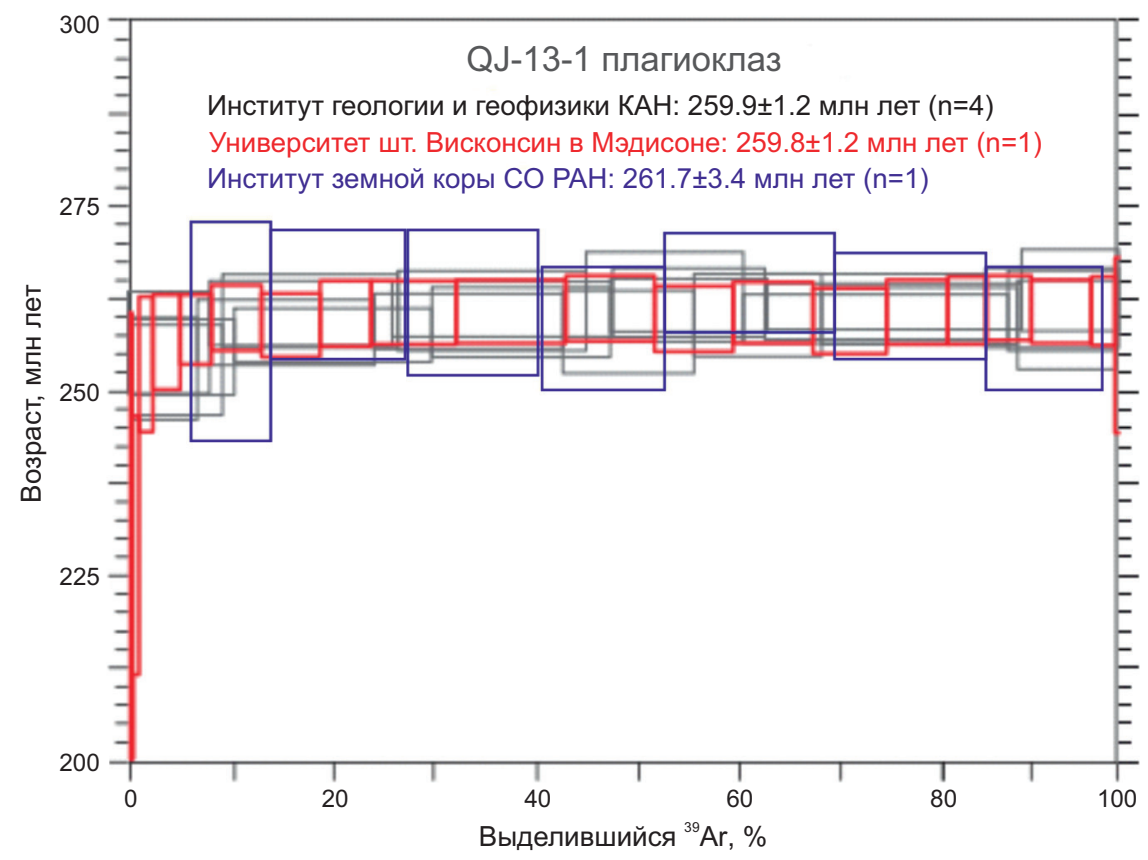

Рис. 16. Диаграмма ступенчатого нагрева для плагиофировых лав Эмейшаньских траппов [Li et al., 2018; Jicha et al., 2019].

${ }^{40} \mathrm{Ar} /{ }^{39} \mathrm{Ar}$ датировки, полученые в трех лабораториях - Института геологии и геофизики Китайской академии наук (Китай) (серый цвет), Университета штата Висконсин в Мэдисоне (США) (красный цвет) и ЦКП «Геодинамика и геохронология» ИЗК СО РАН (Россия) (синий цвет).

Fig. 16. Stepwise heating diagram for plagiophyric lavas of the Emeishan Traps [Li et al., 2018; Jicha et al., 2019].

${ }^{40} \mathrm{Ar} /{ }^{39} \mathrm{Ar}$ datings obtained in three laboratories are shown on the same diagram: at the Institute of Geology and Geophysics of the Chinese Academy of Sciences (China) (gray), the University of Wisconsin-Madison (USA) (red) and at the Center for Geodynamics and Geochronology IEC SB RAS (Russia) (blue color). 


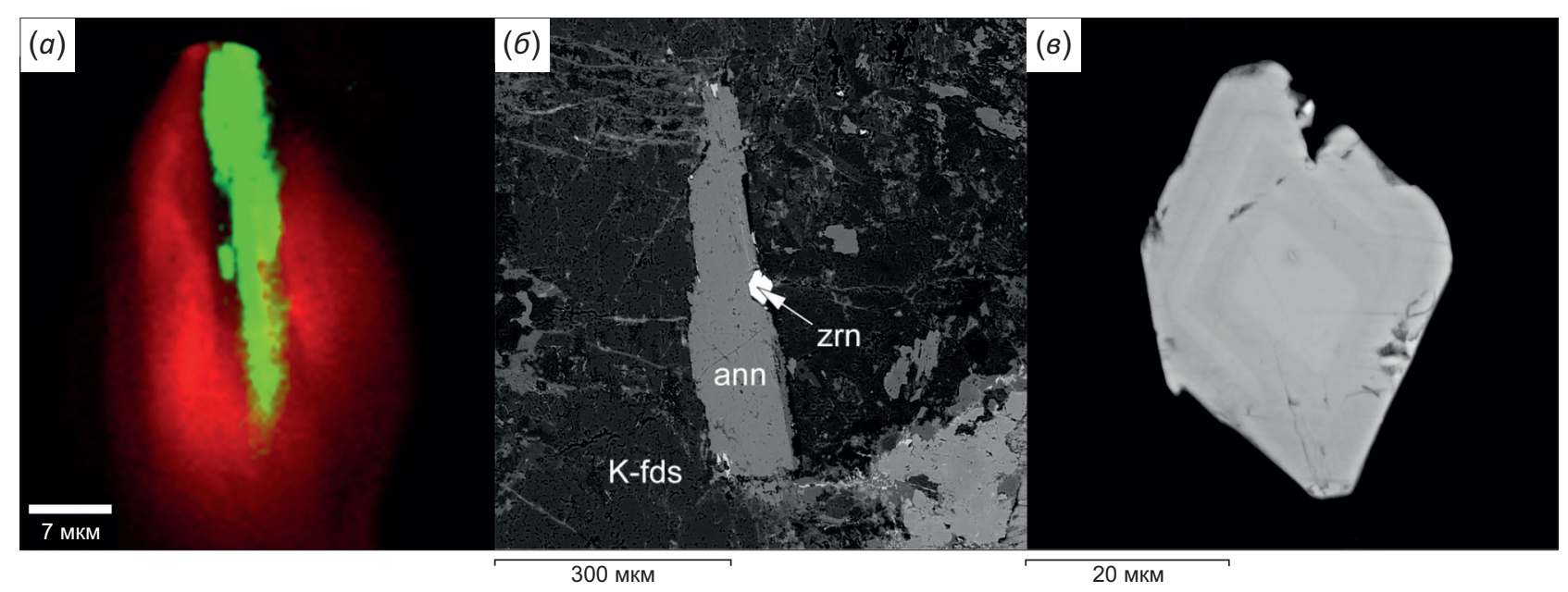

Рис. 17. Результат картирования при помощи $(a)$ конфокальной Рамановской спектроскопии в ЦКП «Геодинамика и геохронология» ИЗК СО РАН и (б), (в) - электронной микроскопии в ЦКП «Изотопно-геохимические исследования» ИГХ СО РАН [Marfin et al., 2021].

На фрагментах $(a)$, (б) и ( 8 ) показано одно и то же зерно циркона. (a) - Рамановское картирование осуществлено на глубине 5 мкм под поверхностью кристалла. Красным цветом показан циркон, зеленым - титанит. (б), (в) - закартирована поверхность кристалла в обратно-рассеянных электронах при разном увеличении. (в) - контрастность подобрана таким образом, чтобы видеть внутреннюю зональность циркона. Аббревиатура на (б) - K-fds - калиевый полевой шпат, ann - aннит, zrn - циркон.

Fig. 17. The result of mapping using $(a)$ confocal Raman spectroscopy at the Center for Geodynamics and Geochronology of the Institute of the Earth's Crust, SB RAS and $(\sigma, 8)$ electron microscopy at the Center of Isotope-Geochemical Research of the Institute of Geochemistry SB RAS [Marfin et al., 2021].

Fragments $(a)$, (б) and $(b)$ show the same zircon grain. In $(a)$, Raman mapping was performed at a depth of $5 \mu \mathrm{m}$ below the crystal surface. Zircon is shown in red and titanite is shown in green. (б) and ( 8 ) show the BSE image of the crystal surface at different magnifications. In ( 8 ), the contrast is selected in such a way as to see the internal zoning of zircon. The abbreviation in (б) - K-fds - potassium feldspar, ann - annite, zrn - zircon.

На рис. 17 показан пример картирования зерна циркона с использованием конфокальной Рамановской спектроскопии в сравнении с электронной микроскопией [Marfin et al., 2021]. Благодаря тому, что первый метод позволяет проводить анализ под поверхностью, в зерне циркона на глубине 5 мкм был обнаружен сросток с кристаллом титанита, который не виден при картировании поверхности зерна при помощи электронной микроскопии. Дополнение данных конфокальной Рамановской спектроскопии позволило сделать вывод о метаморфическом, а не магматическом генезисе циркона [Marfin et al., 2021].

Рентгенофлуоресцентный спектрометр T-STAR и автоматизированный испытательный комплекс ACИС установлены в институте в декабре 2021 г.. Их ввод в эксплуатацию является первоочередной задачей.

\section{5. ЗАКЛЮЧЕНИЕ}

Предыстория ЦКП «Геодинамика и геохронология» началась как минимум 60 лет назад и заключается в создании в 1961 г. в Институте земной коры, тогда СО АН СССР, отдела аналитических лабораторий. Обновление оборудования началось в 1999 г., наиболее интенсивно оно происходит в последние годы. Благодаря этому ЦКП «Геодинамика и геохронология» является динамично развивающейся структурой, укомплектованной высококвалифицированными кадрами и имеющей разнообразное научное оборудование ведущих отечественных и мировых производителей. Это позволяет как полностью на собственной базе, так и в кооперации с другими российскими и зарубежными организациями проводить исследования мирового уровня с публикацией результатов в ведущих международных изданиях.

\section{6. ЗАЯВЛЕННЫЙ ВКЛАД АВТОРОВ / CONTRIBUTION OF THE AUTHORS}

Все авторы внесли эквивалентный вклад в подготовку публикации.

The authors contributed equally to this article.

\section{7. КОНФЛИКТ ИНТЕРЕСОВ / CONFLICТ OF INTERESTS}

Авторы заявляют об отсутствии у них конфликта интересов. Все авторы прочитали рукопись и согласны с опубликованной версией.

The authors have no conflicts of interest to declare. All authors have read and agreed to the published version of the manuscript.

\section{8. ЛИТЕРАТУРА / REFERENCES}

Akhmetzhanov T.F., Pashkova G.V., Chubarov V.M., Labutin T.A., Popov A.M., 2021. Three Calibration Techniques Combined with Sample-Effective Design of Experiment Based on Latin Hypercube Sampling for Direct Detection of Lanthanides in REE-Rich Ores Using TXRF and WDXRF. 
Journal of Analytical Atomic Spectrometry 36, 224-232. https://doi.org/10.1039/D0JA00264J.

Demonterova E.I., Ivanov A.V., Mikheeva E.A., Arzhannikova A.V., Frolov A.O., Arzhannikov S.G., Bryanskiy N.V., Pavlova L.A., 2017. Early to Middle Jurassic History of the Southern Siberian Continent (Transbaikalia) Recorded in Sediments of the Siberian Craton: Sm-Nd and U-Pb Provenance Study. Bulletin de la Société Géologique de France 188 (1-2), 8. http://dx.doi.org/10.1051/bsgf/20 17009.

Demonterova E.I., Ivanov A.V., Mikheeva E.A., Arzhannikova A.V., Frolov A.O., Arzhannikov S.G., Bryanskiy N.V., Pavlova L.A., Reznitskii L.Z., Zarubina O.V., 2018. Source Provenance and Paleogeographic Conditions during Deposition of Jurassic Continental Sediments in the Southern Part of the Siberian Platform (Implication of Sm-Nd and U-Pb Data). Doklady Earth Sciences 480, 720-724. http://dx.doi. org/10.1134/S1028334X18060235.

Donskaya T.V., Gladkochub D.P., Ernst R.E., Pisarevsky S.A., Mazukabzov A.M., Demonterova E.I., 2018. Geochemistry and Petrogenesis of Mesoproterozoic Dykes of the Irkutsk Promontory, Southern Part of the Siberian Craton. Minerals 8 (12), 545. https://doi.org/10.3390/min8120545.

Donskaya T.V., Gladkochub D.P., Fedorovsky V.S., Sklyarov E.V., Cho M., Sergeev S.A., Demonterova E.I., Mazukabzov A.M., Lepekhina E.N., Cheong W., Kim J., 2017. Pre-collisional ( $>0.5 \mathrm{Ga}$ ) Complexes of the Olkhon Terrane (Southern Siberia) as an Echo of Events in the Central Asian Orogenic Belt. Gondwana Research 42, 243-263. https://doi.org/10. 1016/j.gr.2016.10.016.

Gladkochub D.P., Donskaya T.V., Sklyarov E.V., Kotov A.B., Vladykin N.V., Pisarevsky S.A., Larin A.M., Salnikova E.B. et al., 2017. The Unique Katugin Rare-Metal Deposit (Southern Siberian Craton): An Age and Genesis Constrains. Ore Geology Reviews 91, 246-263. https://doi.org/10.1016/j.oregeo rev.2017.10.002.

Gladkochub D.P., Dorofeeva R.P., 2019. Institute of the Earth's Crust. Pages of History 1949-2019. IEC SB RAS, Irkutsk, 795 p. (in Russian) [Гладкочуб Д.П., Дорофеева Р.П. Институт земной коры. Страницы истории, 1949-2019. Иркутск: ИЗК СО РАН, 2019. 795 с.].

Ivanov A.V., Corfu F., Kamentsky V.S., Marfin A.E., Vladykin N.V., 2021. ${ }^{207} \mathrm{~Pb}$-Excess in Carbonatitic Baddeleyite as the Result of Pa Scavenging from the Melt. Geochemical Perspectives Letters 18, 11-15. https://doi.org/10.7185/ geochemlet.2117.

Ivanov A.V., Demonterova E.I., Savatenkov V.M., Perepelov A.B., Ryabov V.V., Shevko A.Y., 2018. Late Triassic (Carnian) Lamproites from Noril'sk, Polar Siberia: Evidence for Melting of the Recycled Archean Crust and the Question of Lamproite Source for Some Placer Diamond Deposits of the Siberian Craton. Lithos 296-299, 67-78. https://doi. org/10.1016/j.lithos.2017.10.021.

Ivanov A.V., Levitskii I.V., Levitskii V.I., Corfu F., Demonterova E.I., Reznitskii L.Z., Pavlova L.A., Kamenetsky V.S., Savatenkov V.M., Powerman V.I., 2019. Shoshonitic Magmatism in the Paleoproterozoic of the South-Western Siberian Craton: An Analogue of the Modern Post-collision Setting.
Lithos 328-329, 88-100. https://doi.org/10.1016/j.lithos. 2019.01.015.

Jicha B.R., Singer B.S., Li Y.-J., 2019. Intercalibration of ${ }^{40} \mathrm{Ar} /{ }^{39} \mathrm{Ar}$ Laboratories in China, the USA and Russia for Emeishan Volcanism and the Guadalupian-Lopingian Boundary. National Science Review 6 (4), 614-616. https:// doi.org/10.1093/nsr/nwz044.

Khudonogova E.V., Suvorova D.S., Revenko A.G., 2015. $\mathrm{X}$-Ray Fluorescence Determination of Cs, Ba, La, Ce, and Nd Concentrations in Rocks of Various Compositions. Analytics and Control 19 (4), 347-356 (in Russian) [Худоногова Е.В., Суворова Д.С., Ревенко А.Г. Рентгенофлуоресцентное определение содержаний Cs, Ba, La, Ce и Nd в горных породах разнообразного состава // Аналитика и контроль. 2015. Т. 19. № 4. С. 347-356] http://dx.doi.org/ 10.15826/analitika.2015.19.4.009.

Kutyrev A.V., Kamenetsky V.S., Park J.W., Maas R., Demonterova E.I., Antsiferova T.N., Ivanov A.V., Hwang J., Abersteiner A., Ozerov A.Yu., 2021. Primitive High-K Intraoceanic Arc Magmas of Eastern Kamchatka: Implications for Paleo-Pacific Tectonics and Magmatism in the Cretaceous. Earth-Science Reviews 220, 103703. https://doi.org/10.1016/j.earscirev. 2021.103703.

Li Y.-J., He H.-Y., Ivanov A.V., Demonterova E.I., Pan Y.-X., Deng C.-L., Zheng D.-W., Zhu R.-X., 2018. ${ }^{40} \mathrm{Ar} /{ }^{39} \mathrm{Ar}$ Age of the Onset of High-Ti Phase of the Emeishan Volcanism Strengthens the Link with the End-Guadalupian Mass Extinction. International Geology Review 60 (15), 1906-1917. https:// doi.org/10.1080/00206814.2017.1405748.

Maltsev A.S., Ivanov A.V., Pashkova G.V., Marfin A.E., Bishaev Y.A., 2021. New Prospects to the Multi-Elemental Analysis of Single Microcrystal of Apatite by Total-Reflection X-Ray Fluorescence Spectrometry. Spectrochimica Acta Part B: Atomic Spectroscopy 184, 106281. https://doi.org/10. 1016/j.sab.2021.106281.

Marfin A.E., Radomskaya T.A., Ivanov A.V., Kamenetsky V.S., Kamenetsky M.B., Yakich T.Yu., Gertner I.F., Kamo S.L. et al., 2021. U-Pb Dating of Apatite, Titanite and Zircon of the Kingash Mafic-Ultramafic Massif, Kan Terrane, Siberia: from Rodinia Break-up to the Reunion with the Siberian Craton. Journal of Petrology 62 (9), egab049. https://doi.org/10. 1093/petrology/egab049.

Pashkova G.V., Mukhamedova M.M., Chubarov V.M., Maltsev A.S., Amosova A.A., Demonterova E.I., Mikheeva E.A., Shergin D.L., Pellinen V.A., Teten'kin A.V., 2021. Comparative Analysis of X-Ray Fluorescence Methods for Elemental Composition Determination of the Archaeological Ceramics from Low Sample Quantity. Analytics and Control 25 (1), 20-33 (in Russian) [Пашкова Г.В., Мухамедова М.М., Чубаров В.М., Мальцев А.С., Амосова А.А., Демонтерова Е.И., Михеева Е.А., Шергин Д.Л., Пеллинен В.А., Тетенькин А.В. Сравнительный анализ методик рентгенофлуоресцентного определения элементного состава археологической керамики из малых навесок // Аналитика и контроль. 2021. T. 25. № 1. C. 20-33]. http://dx.doi.org/10.15826/ analitika.2020.25.1.001.

Pellinen V., Cherkashina T., Gustaytis M., 2021a. Assessment of Metal Pollution and Subsequent Ecological Risk in 
the Coastal Zone of the Olkhon Island, Lake Baikal, Russia. Science of the Total Environment 786, 147441. https://doi. org/10.1016/j.scitotenv.2021.147441.

Pellinen V.A., Cherkashina T.Y., Ukhova N.N., Komarova A.V., 2021b. Role of Gravitational Processes in the Migration of Heavy Metals in Soils of the Priolkhonye MountainSteppe Landscapes, Lake Baikal: Methodology of Research. Agronomy 11 (10), 2007. https://doi.org/10.3390/agrono my11102007.

Revenko A.G., 2014. Physical and Chemical Methods of Researching Rocks and Minerals in the Analytical Centre of the Institute of the Earth's Crust, SB RAS. Geodynamics \& Tectonophysics 5 (1), 101-114 (in Russian) [Ревенко А.Г. Физические и химические методы исследования горных пород и минералов в аналитическом центре ИЗК СО РАН // Геодинамика и тектонофизика. 2014. Т. 5. № 1. C. 101-114]. https://doi.org/10.5800/GT-2014-5-1-0119.

Reznitsky L.Z., Shkol'nik S.I., Ivanov A.V., Demonterova E.I., Letnikova E.F., Hung C.-H., Chung S.-L., 2015. The Hercynian Ikat Thrust in the Transbaikalian Segment of the Central Asian Orogenic Belt. Russian Geology and Geophysics 56 (12), 1671-1684. https://doi.org/10.1016/j. rgg.2015.11.002.

Savelyeva V.B., Demonterova E.I., Danilova Y.V., Bazarova E.P., Ivanov A.V., Kamenetsky V.S., 2016. New Carbonatite Complex in the Western Baikal Area, Southern Siberian Craton: Mineralogy, Age, Geochemistry, and Petrogenesis. Petrology 24, 271-302. https://doi.org/10.1134/S0869591 116030061.

Shendrik R., Kaneva E., Radomskaya T., Sharygin I., Marfin A., 2021. Relationships between the Structural, Vibrational, and Optical Properties of Microporous Cancrinite. Crystals 11 (3), 280. https://doi.org/10.3390/cryst110 30280.

Sheth H., Vanderkluysen L., Demonterova E.I., Ivanov A.V., Savatenkov V.M., 2019. Geochemistry and ${ }^{40} \mathrm{Ar} /{ }^{39} \mathrm{Ar}$ Geochronology of the Nandurbar-Dhule Mafic Dyke Swarm:
Dyke-Sill-Flow Correlations and Stratigraphic Development across the Deccan Flood Basalt Province. Geological Journal 54 (1), 157-176. https: //doi.org/10.1002/gj.3167.

Sklyarov E.V., Dorofeeva R.P., 2009. Institute of the Earth's Crust: People, Events, Dates, 1949-2009. IEC SB RAS, Irkutsk, 672 p. (in Russian) [Скляров Е.В., Дорофеева Р.П. Институт земной коры: люди, события, даты, 1949-2009. Иркутск: ИЗК СО РАН, 2009. 672 с.].

Suvorova D.S., Khudonogova E.V., Revenko A.G., 2014. Development of Technique for the Determination of Ta Concentration in Rocks of Different Composition by X-Ray Fluorescence. Analytics and Control 18 (1), 23-30 (in Russian) [Суворова Д.С., Худоногова Е.В., Ревенко А.Г. Разработка методики рентгенофлуоресцентного определения содержаний Та в горных породах разнообразного состава // Аналитика и контроль. 2014. Т. 18. № 1. С. 23-30]. http://dx.doi.org/10.15826/analitika.2014.18.1.002.

Suvorova D.S., Khudonogova E.V., Revenko A.G., 2016. Development of the XRF Determination Technique for the $\mathrm{Ga}$, Hf and Ta Contents in Rare-Earth Ores. Analytics and Control 20 (4), 344-354 (in Russian) [Суворова Д.С., Худоногова Е.В., Ревенко А.Г. Разработка методики рентгенофлуоресцентного определения содержаний $\mathrm{Ga}, \mathrm{Hf}$ и Та в редкоземельных рудах // Аналитика и контроль. 2016. T. 20. № 4. С. 344-354]. https://doi.org/10.15826/ analitika.2016.20.4.009.

Suvorova D.S., Khudonogova E.V., Revenko A.G., 2017. $\mathrm{X}$-Ray Fluorescence Determination of $\mathrm{Cs}, \mathrm{Ba}, \mathrm{La}, \mathrm{Ce}, \mathrm{Nd}$, and Ta Concentrations in Rocks of Various Composition. X-Ray Spectrometry 46 (3), 200-208. https://doi.org/10.1002/ XRS.2747.

Vanin V.A., Chugaev A.V., Demonterova E.I., Gladkochub D.P., Mazukabzov A.M., 2018. Geologic Structure of the Mukodek Gold Field (Northern Transbaikalia) and Sources of Matter (Pb-Pb and Sm-Nd Data). Russian Geology and Geophysics 59 (9), 1078-1086. https://doi.org/10.1016/j.rgg.2018. 08.002 . 